\title{
A case of recurrent bloody tears
}

This article was published in the following Dove Press journal:

Clinical Ophthalmology

28 July $201 \mathrm{I}$

Number of times this article has been viewed

\section{Șafak Karslıoğlu' \\ İlke Bahçeci Șimșek² \\ Müslime Akbaba' \\ 'Istanbul Oculoplastic and Orbital Surgery and Ocular Oncology Center, ${ }^{2}$ Ophthalmology Department, Medicine Hospital, İstanbul, Turkey}

\begin{abstract}
Well-known causes of blood-tinged epiphora are conjunctival lesions, tumors of the lacrimal apparatus, and systemic bleeding disorders. We describe an unusual patient who presented with recurrent episodes of bloody tearing which began following an erythema multiforme-like drug eruption. He experienced chronic conjunctivitis which resulted in a few minor symblephara. One year later, the patient developed attacks of bloody tearing. All clinical, radiologic, and laboratory investigations related to bloody epiphora were within normal limits except for a mild, nonspecific chronic inflammatory reaction in the perivascular tissues of the lacrimal gland and orbital soft tissues. Also, an increase in vascular permeability and contrast extravasation on carotid angiography was detected. High-dose vitamin $\mathrm{C}$ was administered. The patient continued to have unilateral bloody tears intermittently for two years, but the episodes became much less frequent and had resolved by three years. It is conceivable that increased vascular permeability following the systemic inflammatory process could have played a role in the etiology of recurrent bloody tears in this atypical patient.
\end{abstract}

Keywords: bloody tears, erythema multiforme, drug eruption, vitamin $\mathrm{C}$

\section{Introduction}

Bloody tears is an uncommon clinical occurrence that is usually associated with trauma or lesions of the cornea, conjunctiva, lacrimal gland or sac, and systemic diseases. ${ }^{1-4}$ We report a case of a 24-year-old male who presented with bloody tears following an attack of erythema multiforme-like drug eruption.

\section{Case report}

A 24-year-old man was referred from the dermatology clinic with a diagnosis of erythema multiforme-like drug eruption that developed after receiving cefazolin sodium $1000 \mathrm{mg}$ intravenously for an upper respiratory tract infection. The patient had no family history of any ocular or systemic disease. He developed severe chronic conjunctivitis in his left eye, which resulted in minor symblephara and dry eye after 10 months. The dry eye was controlled with hourly administration of preservative-free artificial tears and punctual plug insertion.

One year later, the patient developed recurrent bloody tears in his left eye and several hematomas in the left periorbital region (Figure 1A). During one of the attacks, he had hemorrhage from the left external auditory meatus and epistaxis on several occasions (Figure 1B). Complete ophthalmologic examination was within normal limits, except for severe dry eye and symblephara on the left side. The right side also had mild dry eye manifestations. Best corrected visual acuity was 20/20 bilaterally. 


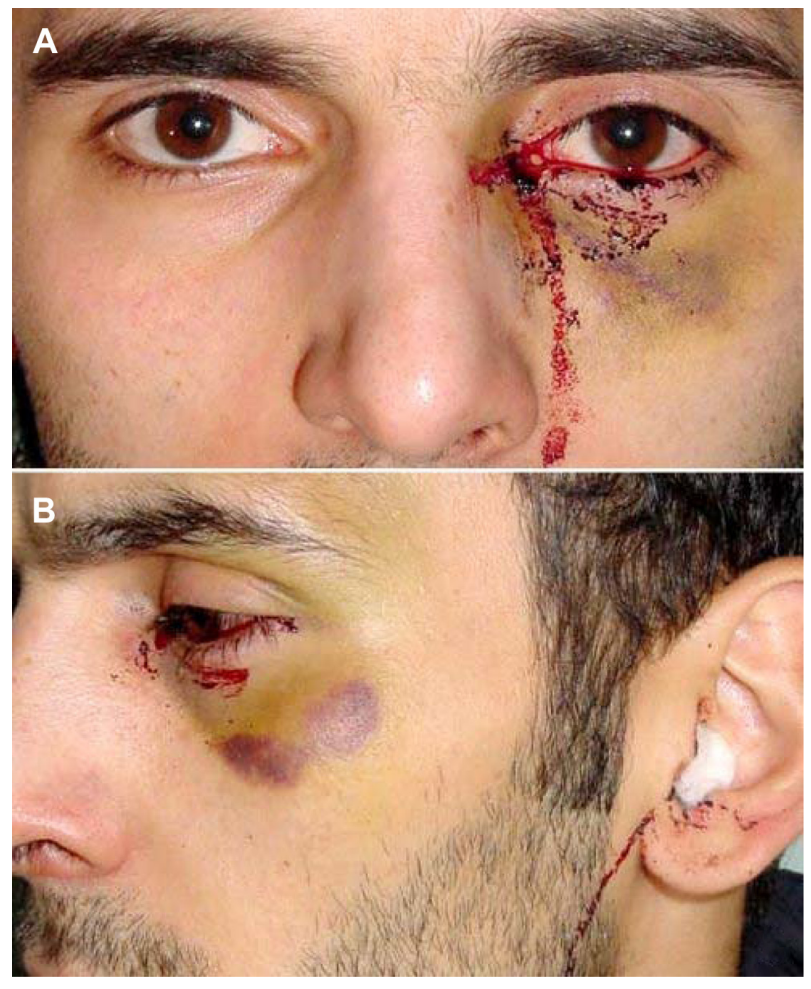

Figure I (A) Bloody tears in the left eye and hematomas on left periorbital region. (B) During attacks, the patient had hemorrhage from the left external auditory meatus and epistaxis.

Complete blood cell count and coagulation tests, including prothrombin time, partial thromboplastin time, bleeding time, and international normalized ratio were all within normal limits. He was widely investigated for rheumatologic disorders, collagen tissue diseases, and vasculitic conditions. Advanced investigations, including anti-Jo-1, anti-RNP, anti-Scl-70, anti-Sm, anti-SS-A, anti-SS-B, antinuclear antibodies, perinuclear antineutrophil cytoplasmic antibodies, PR3, anticardiolipin, IgM, and IgG were within normal limits. Psychiatric examination was normal. Ear, nose, and throat examination performed during attacks of epistaxis revealed blood in the inferior meatus, but the exact location of the hemorrhage could not be located. Imaging, including computerized tomography and magnetic resonance imaging of the cranium and orbital regions, in addition to transcanalicular endoscopic evaluation of the lacrimal drainage system, revealed no pathology. The lacrimal sac and surrounding tissues were explored and multiple biopsies were obtained from the lacrimal sac, ethmoidal mucosa, and angular vein. Nonspecific chronic inflammatory cells were detected in the soft tissues, and angular vein biopsy was normal. Immunohistochemical studies were not contributory. A left carotid and ophthalmic artery angiography was performed in order to evaluate the vascular structure in vivo. Angiography showed small vascular dilatations, and an increase in vascular permeability at the medial canthal and inferior palpebral regions (Figure 2).

Vitamin C $1000 \mathrm{mg}$ daily for one month was prescribed. The patient continued to have unilateral bloody tears intermittently, but the episodes became less frequent and then stopped after three years.

\section{Discussion}

Bloody tearing is a rare clinical phenomenon that may be caused by a wide range of pathologies. The association of this entity with conjunctival lesions, including vascular tumors and malformations, ${ }^{1}$ chronic actinomyces canaliculitisrelated punctal pyogenic granuloma, ${ }^{3}$ and hereditary hemorrhagic telangiectasis, ${ }^{2}$ have been reported in isolated cases. Tumors of the lacrimal apparatus have also been known to cause bloody tears. ${ }^{4}$ Other reported causes include corneal vascular lesions, ${ }^{2}$ vicarious ocular menstruation, ${ }^{5}$ severe epistaxis with regurgitation through the lacrimal passages, ${ }^{6}$ and orbital varix. ${ }^{7}$ Self-inflicted wounds of the conjunctiva causing bloody tears have been reported. ${ }^{8}$ In addition, cases of idiopathic bloody tearing which classically resolve without treatment are known to exist. ${ }^{9}$

In this case, we could not identify any local cause or a systemic condition to explain the finding. The only positive finding resulting from the extensive investigation was the presence of chronic perivascular inflammatory infiltrates in the soft tissues around the lacrimal drainage apparatus, and dilatation and extravasation in the terminal branches of the external carotid ophthalmic artery system. Even though the patient had a diagnosis of erythema multiforme-like drug

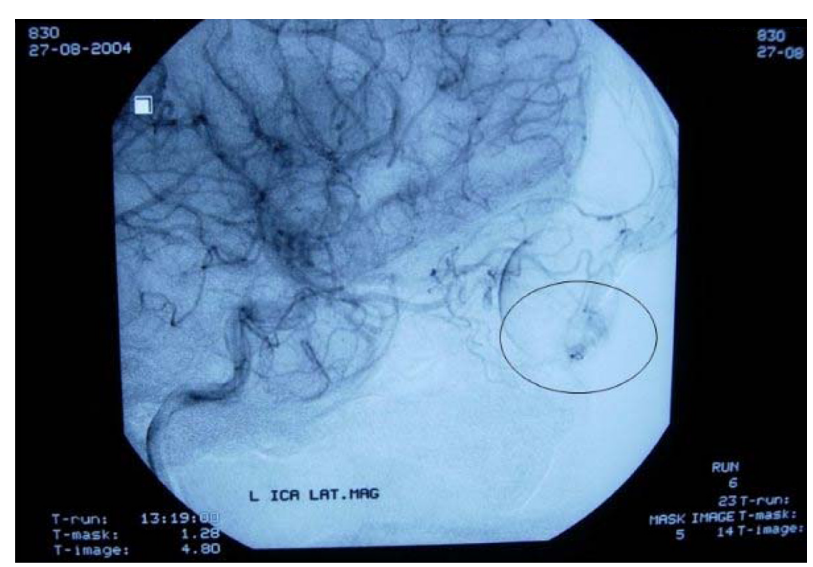

Figure 2 Increased vascular permeability and contrast extravasation on left external carotid and ophthalmic artery angiography. 
eruption from dermatologic evaluation, the ophthalmologic appearance was more consistent with erythema multiforme or Stevens-Johnson syndrome. We speculate that although erythema multiforme is a pathology of small dermal vessels, larger blood vessels are known to show vasculitis and perivasculitis. ${ }^{10}$ Episodic conjunctival inflammation after Stevens-Johnson syndrome was described by Foster et al. They reported that ultrastructural and immunopathologic characteristics of the conjunctiva in these patients were totally different from those without recurrent conjunctivitis, suggesting an immunologically-mediated active inflammation resulting in vasculitis or perivasculitis. ${ }^{10}$ In this case, it is conceivable that bloody tearing may have been a result of increased vascular permeability in the peripalpebral area and the medial canthal region due to disturbed vascular hemodynamics.

It is assumed that spontaneous generation of superoxide is increased in patients with vasculitic diseases. Free oxygen radicals have also been shown in vitro to be important in the pathogenesis of vasculitis and can be reduced with administration of antioxidants like vitamin $\mathrm{C}$, increasing the body's ability to prevent free radical-mediated oxidative damage and improving endothelial dysfunction. ${ }^{12}$ Administration of vitamin C $1000 \mathrm{mg}$ daily to promote vascular stabilization might have had a role in controlling the symptoms. On the other hand, the possibility that the decrease in frequency of attacks might represent the natural course of the disease cannot be ruled out.

In conclusion, we suggest that the bleeding might have resulted from increased vascular permeability following the inflammatory process, and it responded well to high dose vitamin $\mathrm{C}$ as an antioxidant. To the best of our knowledge, this is the first report relating increased vascular permeability to the etiology of recurrent bloody tears.

\section{Disclosure}

The authors report no conflicts of interest in this work.

\section{References}

1. Yazici B, Ucan G, Adam G. Cavernous hemangioma of the conjunctiva: case report. Ophthal Plast Reconstr Surg. 2011;27:e27-e28.

2. Soong HK, Pollock DA. Hereditary hemorragic telangiectasia diagnosed by ophthalmologist. Cornea. 2000;19:849-850.

3. Singh CN, Thakker M, Sires BS. Pyogenic granuloma associated with chronic actinomyces canaliculitis. Ophthal Plast Reconstr Surg. 2006;22:224-225.

4. Levine MR, Dinar Y, Davies R. Malignant melanoma of the lacrimal sac. Ophthalmic Surg Lasers. 1996;27:318-320.

5. Barat M, Kwedar SA. Ocular vicarious menstruation. J Pediatr Ophthalmol Strabismus. 1988;25:254-255.

6. Wiese MF. Bloody tears, and more! An unusual case of epistaxis Br J Ophthalmol. 2003;87:1051.

7. Bonavolonta G, Sammartino A. Bloody tears from an orbital varix. Ophthalmologica. 1981;182:5-6.

8. Awan S, Kazmi HS, Awan AA. An unusual case of bloody tears. Y Ayub Med Coll Abbottabad. 2006;1:68-69.

9. Ho VH, Wilson MW, Linder JS, et al. Bloody tears of unknown cause. Ophthal Plast Reconstr Surg. 2004;6:442-447.

10. Foster CS, Fong LP, Azar D, Kenyon KR. Episodic conjunctival inflammation after Stevens-Johnson syndrome. Ophthamology. 1988;95: 453-462.

11. Mondino BJ. Cicatricial pemphigoid and erythema multiforme. Ophthalmology. 1990;97:939-952.

12. Deng YB, Xiang HJ, Chang Q. Evaluation by high-resolution ultrasonography of endothelial function in brachial artery after Kawasaki disease and the effects of intravenous administration of vitamin $\mathrm{C}$. Circ J. 2002;66:908-912.
Clinical Ophthalmology

\section{Publish your work in this journal}

Clinical Ophthalmology is an international, peer-reviewed journal covering all subspecialties within ophthalmology. Key topics include: Optometry; Visual science; Pharmacology and drug therapy in eye diseases; Basic Sciences; Primary and Secondary eye care; Patien Safety and Quality of Care Improvements. This journal is indexed on

\section{Dovepress}

PubMed Central and CAS, and is the official journal of The Society of Clinical Ophthalmology (SCO). The manuscript management system is completely online and includes a very quick and fair peer-review system, which is all easy to use. Visit http://www.dovepress.com/ testimonials.php to read real quotes from published authors. 